\title{
The effects of taurine on various stages of the kindling process: A summary of results
}

\author{
JOHN GAITO \\ York University, 4700 Keele Street, Downsview, Ontario, Canada M3J 1P3
}

\begin{abstract}
Five experiments were conducted in which taurine was administered to rats at various stages in the kindling process. Amygdaloid stimulation was at 100 -microA intensity for 30 sec. Experiments 1, 2, and 3 evaluated the effects of taurine on rats at the clonic convulsion stage with various dosages $(50,100,200$, and $400 \mathrm{mg} / \mathrm{kg}$ weight). Experiments 4 and 5 were concerned with rats at the exploration and behavioral automatism stages (dosages: 50,100 , and $200 \mathrm{mg} / \mathrm{kg}$ weight). Rats at the initial stage (normal exploration) which received taurine intraperitoneally reached the convulsion stage later than did rats injected with physiological saline. Taurine administration had no effect when rats were at the behavioral automatism or clonic convulsion stage. A second set of four experiments were conducted which used 50 , 100 , and $200 \mathrm{mg} / \mathrm{kg}$ dosages and the duration of stimulation was just above latency threshold. The results were similar to the first set; however, the retardation with rats at Stage 1 was not as pronounced.
\end{abstract}

Research indicates that taurine, a sulfur-containing amino acid, moderates or suppresses the effect of seizures induced by cobalt (Van Gelder, 1972); ouabain (Barbeau \& Donaldson, 1974); penicillin, strychnine, conjugated estrogens, alumina cream (Mutani, Bergamini, Delsedime, \& Durelli, 1974; Mutani, Bergamini, Fabriello, \& Delsedime, 1974); and low calcium (Kaczmarek \& Adey, 1974). Taurine has been reported also to have a beneficial effect on some human epileptic conditions (Barbeau \& Donaldson, 1974; Bergamini, Mutani, Delsedime, \& Durelli, 1974). In both epileptic human cortical foci (Van Gelder, Sherwin, \& Rasmussen, 1972) and cobalt-induced epileptic-type cortical foci in various animals (Craig \& Hartman, 1973; Koyama, 1972; Van Gelder, 1972), taurine deficits and other amino acid level modifications have been reported. Administration of taurine produced a decrease in the abnormalities of amino acid levels in the brain of animals (Van Gelder, 1972) and, to a lesser extent, in humans as well (Van Gelder, Sherwin, Sacks, \& Andermann, 1975). Although the exact function of taurine is unknown, it is assumed to have an important synaptic role, viz, as an inhibitory neurotransmitter, modulator, or membrane stabilizer (Barbeau \& Donaldson, 1974; Davison \& Kaczmarek, 1971; Haas \& Hosli, 1973).

The present study was concerned with the anticonvulsant potential of taurine with another experimentally induced seizure, the "kindling effect" (Goddard, McIntyre, \& Leech, 1969). This procedure involves low-intensity electrical stimulation of a specific brain site periodically, and the behavioral response changes in an orderly fashion. For example, stimulation

This research was supported by a grant from the Ontario Society for Crippled Children. In the conduct of these experiments, the following personnel were involved: the author, Olive Gaito, Stephen Gaito, and Paul Sanberg. of the amygdala in a rat effects three stages of behavior. The initial stimulation has little or no effect on the animal (Stage 1-normal exploratory behavior). With further stimulation trials, automatic behaviors result, e.g., eye closure, chewing _(Stage 2-behavioral automatisms). Finally, the stimulations produce complete convulsions (Stage 3-clonic convulsions). This paper describes experiments concerned with the effects of taurine on the behavior of rats at each of these three stages in the kindling process. Results of a preliminary experiment with a few rats suggested that taurine had an inhibitory effect on rats at Stage 1.

\section{SERIES I EXPERIMENTS}

\section{Methods}

In all experiments, the brain coordinates used for the electrode implantation were as in previous experiments (Gaito, 1976): $.5 \mathrm{~mm}$ posterior to bregma, $4.5 \mathrm{~mm}$ from midline, 8.5 $\mathrm{mm}$ from skull. Wistar strain male rats (90 to 130 days old at the beginning of the experiment) had bipolar electrodes implanted into the amygdala (Nichrome wire with trimel coating, $.127 \mathrm{~mm}$ in diam, dipped one time in epoxylite). All electrodes were inspected for electrical adequacy and then inserted into either the right or left hemisphere according to a random process. Subjects were given at least a 1-week postoperative recovery period before the kindling procedures were begun. All rats were stimulated three times per day with a $60-\mathrm{Hz}$ sine wave of $100 \mu \mathrm{A}$ intensity (peak to peak) for a duration of $30 \mathrm{sec}$, using a Lafayette sine wave stimulator. A response was scored as a CC only if the convulsion continued after termination of the current.

Experiment 1. This experiment was concerned with rats brought to the clonic convulsion (CC) point, Stage 3 , and used after three CCs. The rats were stimulated three times daily for 4 days ( $1 \frac{112}{h}$ between stimulations). During the first 2 days, each rat was injected prior to stimulation (six injections over the 2 days). No injections were provided during Days 3 and 4 prior to stimulation.

Each rat was injected intraperitoneally (IP) with saline or one of the taurine dosares $(50 \mathrm{mg}, 100 \mathrm{mg}$, or $200 \mathrm{mg} / \mathrm{kg}$ weight), and brain stimulation began either $5 \mathrm{~min}$ or $30 \mathrm{~min}$ later using the same stimulation conditions as during the preinjection 
Table 1

Effect of Taurine on Rats at Stages 3 and 2 in Series I Experiments

\begin{tabular}{lcc}
\hline & Saline & Taurine \\
\hline & Stage 3: Clonic Convulsions & \\
$\mathrm{n}$ & 21 & 30 \\
Number of CC & 11.7 & 11.6 \\
Latency & 7.0 & 6.0 \\
Duration & 32.1 & 32.5 \\
& Stage 2: Behavioral Automatisms & \\
$\mathrm{n}$ & 6 & 9 \\
First CC & 7.2 & 5.7 \\
Number of CC & 5.9 & 7.2 \\
Number of CC + BA & 11.3 & 11.8 \\
Latency & 11.6 & 13.2 \\
Duration & 22.4 & 23.3 \\
\hline
\end{tabular}

Table 2

Effects of Taurine on Rats at Stage 1 in Series 1 Experiments

Experiment 4

\begin{tabular}{lcrrc} 
& \multicolumn{4}{c}{ Experiment 4} \\
& Saline & \multicolumn{1}{c}{50} & \multicolumn{1}{c}{100} & $\begin{array}{c}\text { All } \\
\text { Taurine }\end{array}$ \\
\hline $\mathrm{n}$ & 5 & 5 & 5 & 10 \\
First CC & 6.0 & 12.2 & 10.4 & $11.3^{*}$ \\
Number of CC & 6.6 & 2.0 & 2.6 & $2.3^{*}$ \\
Number of CC + BA & 9.8 & 5.6 & 5.6 & $5.6^{*}$ \\
Latency & 16.5 & 12.4 & 16.4 & 14.4 \\
Duration & 25.7 & 14.1 & 18.5 & 16.3 \\
\hline \multicolumn{4}{c}{ Experiment 5 } & Experiments 4-5 \\
& Saline & 200 & $\mathrm{~S}$ & $\mathrm{~T}$ \\
\hline $\mathrm{n}$ & 8 & 8 & 13 & 18 \\
First CC & 8.6 & 9.8 & 7.6 & $10.6^{*}$ \\
Number of CC & 4.6 & 3.5 & 5.4 & $2.8^{*}$ \\
Number of CC + BA & 9.4 & 7.3 & 9.5 & $6.3^{*}$ \\
Latency & 10.8 & 9.2 & 13.0 & 12.1 \\
Duration & 15.1 & 23.8 & 20.7 & 19.6 \\
\hline
\end{tabular}

*Statistical significance $(p<.05)$, taurine vs. saline conditions.

period. There were the following number of rats for the saline, 50-, 100-, and $200-\mathrm{mg} / \mathrm{kg}$ conditions, respectively: $5 \mathrm{~min}-$ three, two, four, two: $30 \mathrm{~min}$-four, two, four, two. All solutions were coded prior to injection. Thus the experimenter was unaware of the designation of each rat.

Experiment 2. Procedures in Experiment 2 were similar to those of Experiment 1 with a few exceptions: each rat was run to 10 to $15 \mathrm{CCs}$ and matched for saline and taurine conditions in number of CCs and latency and duration of $\mathrm{CC}$ on the last trial, $200-\mathrm{mg} / \mathrm{kg}$ weight taurine dosage was used, $60 \mathrm{~min}$ was the injection-stimulation interval for Days 1 and 2, and each rat was given two injections of saline or the taurine dosage on each of the 3 days before stimulation began, as well as three injections on Days 1 and 2. There were 12 injections with seven pairs of rats.

Experiment 3. Experiment 3 was the same as Experiment 2 except that each rat received five CCs, was matched on the fifth CC trial, and was injected with a dosage of $400 \mathrm{mg} / \mathrm{kg}$ weight $60 \mathrm{~min}$ prior to stimulation. Again there were seven pairs of rats.

Experiment 4. Experiment 4 was concerned with rats at Stages 1 and 2 (normal exploration-NE, behavioral automationsBA) of the kindling process. Rats were given two stimulation trials to determine whether behavior was that of Stage 1 or Stage 2 . Within each stage, the rats were matched for saline or one of two taurine dosages $(50 \mathrm{mg}, 100 \mathrm{mg} / \mathrm{kg}$ weight). Rats were injected three times on Days 1 and 2,60 min prior to stimulation. Three sets of matched rats were used for the three conditions at Stage 2, and five sets at Stage 1.

Experiment 5. Experiment 5 was the same as Experiment 4 except that the dosage was $200 \mathrm{mg} / \mathrm{kg}$ weight and two injections were added on the 3 days prior to stimulation. Thus, there were 12 injections for three pairs of rats at Stage 2 and for eight pairs at Stage 1.

\section{Results and Discussion}

The results for all experiments are shown in Tables 1 and 2. For the CC stage, there were no apparent differences between the various injection-stimulation intervals or the various dosages; thus all taurine animals were combined (Table 1). No differences appear in the mean values for any of the dependent variables used: number of CCs, latency of CC, duration of CC. The mean values for the three dependent variables are remarkably similar for saline and taurine rats.

Table 1 demonstrates that taurine appears not to have an effect also when rats are at Stage 2, the stage of automatic behaviors.

It is only when rats are taken at Stage 1 that taurine appears to have an effect (Table 2). Using analyses of variance procedures (two-dimensional design: pairs or triplets, treatments), the two taurine groups differ significantly from the saline group in mean trial of first $\mathrm{CC}$, in mean number of CCs and BAs, and in the mean number of CCs in the 12 stimulation trials $(p<.05)$ in Experiment 4, but do not differ significantly from each other. There are no significant differences for the latency- and duration-dependent variables. There were no statistically significant differences in Experiment 5, but the results go in the same direction as in Experiment 4 . When the data for these two experiments are combined, statistically significant differences $(p<.05)$ appear in the same dependent variables as in Experiment 4.

If one contrasts taurine with saline within pairs or triplets, the result is a clear one. In Experiment 4, both taurine members in each of the five triplets go in the direction of retardation (relative to the saline rat). Thus either could be used for pairing purposes and produces the same result. Over Experiment 4 and 5, in 12 of 13 pairs, $\mathrm{S}>\mathrm{T}$ in the number of $\mathrm{BA}$ and $\mathrm{CC}$; in number of $\mathrm{CC}, \mathrm{S}>\mathrm{T}$ in 11 of 13 pairs; in number of trials to first CC. T > S in 11 of 13 pairs. Such differences are highly significant using a binomial distribution in the test of null hypotheses.

An evaluation of behavior on days of receiving taurine (Days 1 and 2) with those of no taurine administration (Days 3 and 4) shows no difference when rats are at Stages 2 or 3. Such comparison for animals at Stage 1 is not meaningful. Likewise, the 3 days of two injections prior to stimulation produced no retarding or moderating effect for rats at Stages 2 or 3. At Stage 1, the inclusion of six injections prior to the 1st day of stimulation did not enhance the retardation effect. 


\section{SERIES II EXPERIMENTS}

The results of the Series I experiments seemed to show clearly that taurine does have a retarding effect, but only with naive rats (i.e., those at Stage 1, prior to the occurrence of any automatic behaviors). Some chemicals have been successful in affecting rats at each of these stages. For example. Fried and McIntyre (1973) reported that $\Delta$-9-trans-tetrahydrocannabinol (THC) both suppressed convulsions and retarded the rate of development of convulsions. These individuals used $50-\mu \mathrm{A}$ stimulation for $5 \mathrm{sec}$. It is possible that the duration of stimulation which we used $(30 \mathrm{sec})$ is too long and that if shorter durations were involved (e.g., 1 to 5 $\mathrm{sec}$ ), there might be an effect at Stages 2 and 3 also. Thus four further experiments were conducted using shorter durations of stimulation.

\section{Methods}

Experiments 1 and 2. The subjects were Wistar strain rats (130 to 200 days old at the beginning of the experiment) which had achieved 10 to $15 \mathrm{CCs}$. The rats were matched for saline and taurine conditions in number of CCs and latency and duration of CC on the last trial. In Experiment 1, five pairs of rats were injected IP with saline or taurine $(200 \mathrm{mg} / \mathrm{kg}$ weight $)$ and brain stimulation began $1 \mathrm{~h}$ later. Intensity was $100 \mu \mathrm{A}$; duration varied from 1 to $5 \mathrm{sec}$ : in each case, the duration was slightly above the latency which was obtained on the last preinjection trial. In Experiment 2, eight pairs were used and $100 \mathrm{mg} / \mathrm{kg}$ weight was the dosage; durations varied from 7 to $10 \mathrm{sec}$.

The rats were stimulated three times daily for 4 days $\left(1 \frac{1 / 2}{2}\right.$ $\mathrm{h}$ between stimulations). During the first 2 days, each rat was injected $60 \mathrm{~min}$ prior to stimulation (six injections). No injections were provided during Days 3 and 4 prior to stimulation.

Experiments 3 and 4. Nonstimulated rats similar to those in Experiments 1 and 2 were used. They were given two stimulation trials to determine whether behavior was that of Stage 1 or Stage 2. Within each stage, the rats were matched for saline or taurine conditions. In Experiment $3,100 \mathrm{mg} / \mathrm{kg}$ weight was the dosage with six pairs of rats. In Experiment $4,50 \mathrm{mg} / \mathrm{kg}$ was used with six pairs. The injection and brain stimulation procedures were the same as in Experiments 1 and 2. In Experiments 3 and 4, rats which had not convulsed after Trial 12 were continued for 2 more days to a maximum of 18 trials. If no CC was attained, an estimated value for number of trials to first CC was provided by adding six for those at Stage 1 and three for those at Stage 2. Then the placement of the electrode of each of these nonconvulsing rats was evaluated by visual observation with a magnifying lens, prior to determining whether the rat had received taurine or saline. In Experiment 4, one pair of rats was deleted because the electrode in each was not in the amygdala.

\section{Results and Discussion}

The results for all experiments are shown in Table 3 as mean values. For the CC stage, there were no differences between the $100-$ and $200-\mathrm{mg} / \mathrm{kg}$ dosages; thus animals were combined. As in Series I, no differences appeared in any of the dependent variables used: number of CCs, latency of CC, duration of CC.

There were only two pairs of rats at Stage 2 in each of Experiments 3 and 4 . There were no differences between saline and taurine conditions in trials of first CC in each experiment, as was the case in Series I.
Table 3

Effect of Taurine on Rats at Three Stages

in Series II Experiments

\begin{tabular}{|c|c|c|c|c|}
\hline & & Saline & Taurine & \\
\hline \multicolumn{5}{|c|}{ Stage 3: Clonic Convulsions } \\
\hline $\mathrm{n}$ & & 13 & 13 & \\
\hline Number of $\mathrm{CC}$ & & 10.2 & 10.2 & \\
\hline Latency & & 8.0 & 8.5 & \\
\hline Duration & & 30.9 & 31.8 & \\
\hline \multicolumn{5}{|c|}{ Stage 2: Behavioral Automatisms } \\
\hline \multirow{4}{*}{$\begin{array}{l}\mathrm{n} \\
\text { First CC } \\
\end{array}$} & & 4 & \multirow{2}{*}{\multicolumn{2}{|c|}{$\begin{array}{l}4 \\
7.0\end{array}$}} \\
\hline & & 6.3 & & \\
\hline & \multicolumn{2}{|c|}{$100 \mathrm{mg} / \mathrm{kg}$} & \multicolumn{2}{|c|}{$50 \mathrm{mg} / \mathrm{kg}$} \\
\hline & Saline & Taurine & Saline & Taurine \\
\hline \multicolumn{5}{|c|}{ Stage 1: Normal Exploration } \\
\hline $\mathrm{n}$ & 6 & 6 & 5 & 5 \\
\hline \multirow[t]{3}{*}{ First CC } & 13.5 & 14.5 & $7.4^{*}$ & $16.2^{*}$ \\
\hline & \multicolumn{4}{|c|}{ Combined } \\
\hline & & Saline & Taurine & \\
\hline $\mathrm{n}$ & & 11 & 11 & \\
\hline First CC. & & 10.8 & 15.3 & \\
\hline
\end{tabular}

*Differences significant at p level below .05 .

At the exploration stage, the taurine group required a greater number of trials to reach the convulsive stage for both $100-\mathrm{mg} / \mathrm{kg}$ and $50-\mathrm{mg} / \mathrm{kg}$ dosages. However, only with the latter dosage was the difference statistically significant using a pairs by treatments analysis of variance procedure $(p<.05)$.

The results of these experiments were similar to those obtained in Series I experiments using $30 \mathrm{sec}$ as the duration of stimulation. However, the results were not as conclusive with rats at the exploration stage as in the previous study.

\section{GENERAL DISCUSSION}

Our results are consistent with those obtained by other researchers (Burnham, Arnold, \& Racine. Note 1; Wada, Osawa, Wake. \& Corcoran, 1975) for rats at the CC stage. However, Burnham et al. (Note 1) found no differences at the exploratory stage. In any event, it appears clear that, if taurine is to have an effect, it will be early in the kindling process. Our results and those of others suggest that as soon as electrophysiological and neurological changes occur (Goddard, McIntyre, \& Leech, 1969; McIntyre \& Goddard, 1973; Racine, 1972), taurine is ineffective in suppressing or moderating behavioral effects. The inability of taurine to reverse or moderate convulsions produced during kindling is in sharp contrast to the effect of taurine in some human epilepsy cases and in other experimentally induced convulsive events (Barbeau \& Donaldson, 1974; Bergamini, Mutani, Delsedime, \& Durelli, 1974: Kaczmarek \& Adey, 1974; Mutani. Bergamini, Delsedime, \& Durelli, 1974; Mutani, Bergamıni. Fabriello, \& Delsedime, 1974). 
The difference in the two situations probably is based on different mechanisms underlying the two types of events. It appears that neural pathway changes occur during kindling (Goddard, McIntyre, \& Leech, 1969; McIntyre \& Goddard, 1973; Racine, 1972) whereas, in some human epilepsy, or other induced seizures, such drastic changes are not produced. Presumably in the latter case. hypersensitive or irritated cells, but not pathway changes, are involved. Although the kindling process was suggested by some individuals as a model of epilepsy (e.g., Gaito, 1974), the results suggest that the similarity between the two may be only at the behavioral level and that different mechanisms probably underly the two conditions.

Results question the kindling effect as a model of epilepsy in general; however, the classification of epilepsy encompasses a number of diverse conditions. Thus, it is possible that the kindling effect may not represent an adequate model of some types of epilepsy, whereas it may be analogous to other epileptic conditions. Obviously, if one is merely concerned with the kindling effect as a model of the behavioral portion of epilepsy, as in grand mal or petit mal seizures, then the model provides a better fit.

These results are similar to those obtained in other experiments concerning interanimal transfer of the kindling effect (Gaito, 1976). It was found that brain material from kindled rats retarded the development of the clonic convulsion in naive recipients but had no effect on rats which had attained the convulsion stage. Thus, the development of the convulsive mechanism and the triggering mechanism may represent two different processes (Burnham, 1975).

\section{REFERENCE NOTE}

1. Burnham. W. M., Arnold. P., \& Racine, R. J. Effect of tuurine on "kindled" seizures: A preliminary survey. Paper presented at the Annual Meeting of the Clinical Research Society of Toronto. Tornnto. April 5, 1975.

\section{REFERENCES}

Barbeau. A.. \& Donaldson, J. Zinc, taurine, and epilepsy. Archives of Neurology. 1974, 30, 52-58.

Bergamini. L.. Mutani, R., Delsedime, M., \& Durelli, L. First clinical experience on antiepileptic action of taurine. European Neurology, 1974, 11. 261-269.

Burnham, W. M. Primary and "transfer" seizure development in the kindled rat. Canadian Journal of Neurological Sciences, 1975. 2. 417-428.

Craig, C. R., \& Hartman, E. R. Concentration of amino acids in the brain of cobalt-epileptic rat. Epilepsia, 1973, 14, 409-414.

Davison. A. N., \& KaCZMAREK, L. K. Taurine-a possible neurotransmitter? Nature, 1971, 234, 107-108.

Fried, P. A., \& MCINTYRE, D. C. Electrical and behavioral attenuation of the anti-convulsant properties of $\Delta^{9}$.THC following chronic administrations. Psychopharmacologia, 1973, 31. $215-227$.

Garto, J. The kindling effect. Prysiological Psychology, 1974, 2, 45-50.

Garto, J. Pairing of the transfer experiment with the kindling paradigm: A summary of results. Bulletin of the Psychonomic Society. 1976, 7. 50-52.

Goddard, G. V., MCInTYRe, D. C., \& Leech, C. K. A permanent change in brain function resulting from daily electrical stimulation. Experimental Neurology, 1969, 25. 295-330.

HaAs, H. L., \& Hosli, L. The depression of brain stem neurones by taurine and its interaction with strychnine and bicuculline. Brain Research. 1973, 52. 399-402.

Kaczmarex, L. K., \& Adey, W. R. Factors affecting the release of $\left(1^{4} \mathrm{C}\right)$ taurine from cat brain: The electrical effects of taurine on normal and seizure prone cortex. Brain Research, 1974, 76, 83-94.

Koyama, I. Amino acids in the cobalt-induced epileptogenic and nonepileptogenic cats' cortex. Canadian Journal of Physiology \& Pharmacology, 1972, 50, 740-752.

MCINTYRE, D., \& GODDARD, G. V. Transfer, interference and spontaneous recovery of convulsions kindled from rat amygdala. Electroencephalography \& Clinical Neurophysiology, 1973, 35. 533-543.

Mutani, R., Bergamini, L, Delsedime, M., \& Durelli, L. Effects of taurine in chronic experimental epilepsy. Brain Research, 1974, 79. 330-332.

Mutani, R., Bergamini, L., Fariello, R., \& Delsedime, M. Effects of taurine on cortical acute epileptic foci. Brain Research, 1974, 70, 170-173.

RACINE, R. J. Modification of seizure activity by electrical stimulation: II. Motor seizure. Electroencephalography \& Clinical Neurophysiology, 1972, 32, 281-294.

VAN GELDER, N. M. Antagonism by taurine of cobalt induced epilepsy in cat and mouse. Brain Research, 1972, 47, 157.165.

Van Gelder, N. M., Sherwin, A. L., \& Rasmussen, T. Amino acid content of epileptogenic human brain: Focal versus surrounding regions. Brain Research, 1972, 40, 385-393.

Van Gelder, N. M., Sherwin, A. L., Sacks, C., \& Andermann. F. Biochemical observations following administration of taurine to patients with epilepsy. Brain Research. 1975, 94, 297-306.

Wada, J. A., Osawa, T.. Wake, A., \& Corcoran, M. E. Effects of taurine on kindled amygdaloid seizures in rats, cats. and phetosensitive baboons. Epilepsia, 1975. 16. 229-234.

(Received for publication January 9, 1976.) 